\title{
Carbon Composites From Iron-chelating Pyridine Nitrogen-rich Coordinated Nanosheets for Oxygen Reduction
}

\section{Bing Zhang}

Donghua University

Hele Guo

Donghua University

\section{Longsheng Zhang}

Jiangnan University

Xu Zhang ( $\boldsymbol{D}$ xuzhang@dhu.edu.cn )

Donghua University https://orcid.org/0000-0002-8589-7034

Chao Zhang

Donghua University

Tianxi Liu

Donghua University

\section{Research Article}

Keywords: nanosheet composites, pyridinic nitrogen, oxygen reduction reaction, methanol resistance, electrochemical durability

Posted Date: December 2nd, 2021

DOI: https://doi.org/10.21203/rs.3.rs-1116807/v1

License: (9) This work is licensed under a Creative Commons Attribution 4.0 International License. Read Full License

Version of Record: A version of this preprint was published at Functional Composite Materials on March 14th, 2022. See the published version at https://doi.org/10.1186/s42252-022-00030-y. 


\section{Abstract}

The exploration of a noble-metal-free and nitrogen-doped carbon (M-N/C) composite electrocatalyst for the oxygen reduction reaction (ORR) remains a great challenge. The activities of the M-N/C composite electrocatalysts are mainly affected by the metal active sites, pyridinic nitrogen, and graphitic nitrogen. In the present work, the iron-coordinated self-assembly is proposed for the preparation of iron-chelating pyridine nitrogen-rich coordinated nanosheet (IPNCN) composites as an electrocatalyst. Due to the highly conjugated structure of the IPNCN precursor, the pyridine nitrogen elements at both ends of the

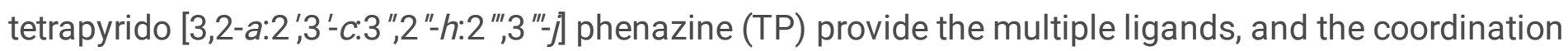
interactions between the irons and the pyridine nitrogen further improve the thermodynamic stability, where the metal active sites and nitrogen elements are uniformly distributed in the whole structure. The resultant IPNCN composites exhibit excellent ORR performance with an onset potential of $0.93 \mathrm{~V}$ and a half potential of $0.84 \mathrm{~V}$. Furthermore, the IPNCN composite electrocatalysts show the higher methanol resistance and electrochemical durability than the commercial $\mathrm{Pt} / \mathrm{C}$ catalysts. It could be convinced that the as-designed IPNCN composite catalysts would be a promising alternative to the noble metal Pt-based catalysts in the practical applications.

\section{Introduction}

The development of highly efficient electrocatalysts for energy technology has been becoming a matter of urgency as the worldwide depletion of fossil fuels and the growing demand in energy source. An enormous amount of research has been devoted for developing the non-noble oxygen reduction reaction (ORR) catalysts. The ORR is the crucial electrochemical process of the energy storage and the conversion devices, including the alkaline fuel cells, metal-air batteries, and proton exchange membrane fuel cells [1, 2]. The Pt-based catalysts are the most effective electrocatalysts for the ORR due to their relatively high current densities and low overpotentials [3, 4]. However, the high cost, sluggish reaction kinetics, poor methanol tolerance, and electrochemical durability have been limiting their large-scale applications in commercialization. Therefore, it is of crucial importance to explore the efficient non-noble metal catalysts with high ORR catalytic performance.

The metal-nitrogen/carbon ( $\mathrm{M}-\mathrm{N} / \mathrm{C}, \mathrm{M}=\mathrm{Fe}, \mathrm{Co}$, and $\mathrm{Ni}$, etc.) electrocatalysts are the most potential composite materials to replace the Pt-based catalysts since the relatively low price, the abundant reserve, the outstanding ORR catalytic performance, and the high stability [5-7]. The metal ions can serve as the catalytic centers, while the heteroatoms boost the electrocatalytic activity. The doped-nitrogen can facilitate the formation of the active $\mathrm{N}-\mathrm{C}$ functional sites [8, 9]. The pyridinic nitrogen (pyridinic- $\mathrm{N}$ ) and the graphitic nitrogen (graphitic- $\mathrm{N}$ ) are able to create the active sites which are considered to be more important factor in the ORR process [10-12]. However, the M-N/C composite catalysts generally meet several key problems, such as the structural damage and instability after carbonization, the low content of pyridinic- $\mathrm{N}$ and graphitic- $\mathrm{N}$, and the difficulty in uniform distribution, etc. Therefore, it is necessary to design and prepare the stable M-N/C precursors from the molecular level with high content of pyridinic-N and graphitic-N to get the uniformly dispersed active sites. 
In the present work, a convenient and stable self-templated method was developed to prepare the electrocatalysts of the iron-chelating pyridine nitrogen-rich coordinated nanosheet (IPNCN) composites. The IPNCN composites are capable of retaining the structural stability during carbonization since that the ligand unit of the tetrapyrido [3,2-a:2', ' $\left.-c: 3^{\prime \prime}, 2^{\prime \prime}-h: 2^{\prime \prime \prime}, 3^{\prime \prime \prime}-j\right]$ phenazine (TP) is a fully conjugated rigid plane and is easily organized into the rigid polymers based on the coordination interactions. The TP has high nitrogen content and is rich in pyridine nitrogen from the structure design at molecular level, which can be evenly distributed in the whole skeleton of the coordination polymers. The pyridine nitrogen at both ends of the TP can form the cross-linked centers with the metal coordination interactions, while the highly conjugated structure of the TP can also create more active sites to effectively improve the electrical conductivity. In addition, the metal atoms also provide uniform and stable catalytic active sites for the ORR. Benefiting from the high content of the pyridinic-N and uniformly distributed active sites, the IPNCN composites exhibit the excellent electrocatalytic activity for the ORR and superior tolerance to methanol in comparison with the commercial Pt/C catalysts.

\section{Experimental}

\section{Materials}

The 1,10-phenanthroline-5,6-dione and ferrous chloride tetrahydrate $\left(\mathrm{FeCl}_{2} \cdot 4 \mathrm{H}_{2} \mathrm{O}, \geq 99 \%\right)$ were purchased from Shanghai Titan Scientific Co., Ltd. The ammonium acetate (>97.0\%) and sodium hydrosulfite (> $85.0 \%$ ) were purchased from $\mathrm{TCl}$ (Shanghai) Development Co., Ltd. The hydrochloric acid ( $\mathrm{HCl}, 37 \%)$, ethanol, and methanol were purchased from the Sinopharm Chemical Regent. The deionized (DI) water was used throughout the experiments. All of the purchased chemicals were used directedly without further purification.

\section{Preparation of the TP}

Typically, the 1,10-phenanthroline-5,6-dione $1.45 \mathrm{~g}$ (6.9 mmol), sodium hydrosulfite $0.15 \mathrm{~g}(0.86 \mathrm{mmol})$, and ammonium acetate $(15 \mathrm{~g})$ were first placed into a dry round bottomed flask under argon, and then heated to $180^{\circ} \mathrm{C}$ for 4 hours with occasional stirring. After cooling to room temperature, the reaction mixtures were added into deionized water $(20 \mathrm{ml})$. Then, the collected precipitations were washed with methanol and water. The obtained products were triturated in refluxing ethanol $(50 \mathrm{ml})$ and filtered immediately, and then washed with ethanol and dried under vacuum. Yield: $0.92 \mathrm{~g} \mathrm{(63.5 \% ).} \mathrm{MALDI-TOF}$ mass calculated for $\mathrm{C}_{24} \mathrm{H}_{12} \mathrm{~N}_{6}[\mathrm{M}+\mathrm{H}]^{+}, 385.11$; found $384.8282 .{ }^{1} \mathrm{H} \mathrm{NMR}\left(400 \mathrm{MHz}, \mathrm{CDCl}_{3}\right): \delta(\mathrm{ppm}) 9.67$ $(\mathrm{d}, J=7.8 \mathrm{~Hz}, 4 \mathrm{H}), 9.37$ (d, $J=2.9 \mathrm{~Hz}, 4 \mathrm{H}), 7.87$ (dd, $J=7.8,4.1 \mathrm{~Hz}, 4 \mathrm{H}) \cdot{ }^{13} \mathrm{C} N \mathrm{NM}\left(100 \mathrm{MHz}, \mathrm{D}_{2} \mathrm{O}\right) \delta$ (ppm) 151.09 (s), 144.95 (s), 137.14 (s), 129.07 (s), 122.51 (s), 119.72 (s).

\section{Preparation of the IPNCN}

Typically, the TP $(61 \mathrm{mg}, 0.16 \mathrm{mmol})$ and $\mathrm{FeCl}_{2} \cdot 4 \mathrm{H}_{2} \mathrm{O}(20 \mathrm{mg}, 0.016 \mathrm{mmol})$ were added into the ethanol/water $(25 \mathrm{ml} / 25 \mathrm{ml})$ mixtures. After stirring for $10 \mathrm{~min}$, the mixtures were transferred into the 80 $\mathrm{mL}$ Teflon-lined stainless-steel autoclave and heated at $90^{\circ} \mathrm{C}$ for $24 \mathrm{~h}$. After being collected by filtration, 
washed with deionized water and ethanol, and then dried at $60^{\circ} \mathrm{C}$, the obtained products were heatedtreated under the $\mathrm{N}_{2}\left(99.99 \%\right.$ Air Liquide) from $30^{\circ} \mathrm{C}$ to $750{ }^{\circ} \mathrm{C}, 800^{\circ} \mathrm{C}, 850^{\circ} \mathrm{C}$, and $900{ }^{\circ} \mathrm{C}$ with a ramp of $5{ }^{\circ} \mathrm{C} / \mathrm{min}$ by remaining the temperature for $2 \mathrm{~h}$. Next, the pyrolyzed products were cooled to room temperature and stirred in the $1 \mathrm{~mol} / \mathrm{L} \mathrm{HCl}$ for $12 \mathrm{~h}$ to remove the free metal particles. Finally, the pyrolyzed products were collected by filtration, washed with deionized water for several times, and then dried at $60^{\circ} \mathrm{C}$.

\section{Characterizations}

The morphologies of the precursors and pyrolyzed products were characterized by the field-emission scanning electron microscopy (FESEM, JEOL S-4800). The structures of the monomers were determined by the ${ }^{1} \mathrm{H}$ NMR spectrum, the ${ }^{13} \mathrm{C}$ NMR spectrum, and the MALDI-TOF mass spectrum. The ${ }^{1} \mathrm{H}$ NMR and

${ }^{13} \mathrm{C}$ NMR spectra were recorded on a Bruker model Bruker AV-400 spectrometer, operating at $400 \mathrm{MHz}$ and $100 \mathrm{MHz}$, respectively. The matrix-assisted laser desorption ionization time-of-flight mass spectrometry (MALDI-TOF mass spectrum) was performed on an AB Sciex model Sciex 4800 plus MALDI-TOF analyzer, using dithranol as the matrix. The $\mathrm{N}_{2}$ adsorption-desorption isotherms of the IPNCN composite materials were obtained by the Micromeritics ASAP-2020 at $77 \mathrm{~K}$. The surface areas and pore size distributions of the tested samples were calculated by the Brunauer-Emmett-Teller (BET) and nonlocal density functional theory method. The X-ray photoelectron spectrometer measurements were conducted on a photoelectron spectrometer.

\section{Electrochemical measurements}

The electrochemical measurements were carried out on a CHI 660C electrochemical workstation with a three-electrode cell (CHI600E, Shanghai, China). The working electrodes were formed by mixing the samples $(5 \mathrm{mg})$ with ethanol $(350 \mu \mathrm{L})$ and Nafion $(95 \mu \mathrm{L})(5 \mathrm{wt} \%)$ by sonication $15 \mathrm{~min}$ to prepare homogeneous catalyst inks. Then, working electrode was prepared by depositing the catalyst ink onto rotating disk electrode ( $5 \mathrm{~mm}$ in diameter). The $\mathrm{Ag} / \mathrm{AgCl}$ ( $3 \mathrm{~mol} / \mathrm{L}$ ) electrodes and graphite rods were employed to act as the reference and counter electrodes, respectively. All the initially tested potentials were converted to a reference hydrogen electrode (RHE) following the equation:

$\mathrm{E}_{\mathrm{RHE}}=\mathrm{E}_{\mathrm{Ag} / \mathrm{AgCl}}+0.197+0.059 * \mathrm{pH}$.

The cyclic voltammetry (CV) tests were performed from -0.2 to $1.2 \mathrm{~V}$ ( $v s$. RHE) at a scan rate of $50 \mathrm{mV} / \mathrm{s}$. The linear sweep voltammetry (LSV) was measured from 0 to $1.2 \mathrm{~V}(\mathrm{vs}$. RHE) at a scan rate of $5 \mathrm{mV} / \mathrm{s}$ with a rotating speed from $800 \mathrm{rpm}$ to $2400 \mathrm{rpm}$ under the $\mathrm{O}_{2}$-saturated circumstance. The current-time (it) tests were evaluated with $1600 \mathrm{rpm}$ at $0.69 \mathrm{~V}$ in the $\mathrm{O}_{2}$-saturated $0.1 \mathrm{~mol} / \mathrm{L} \mathrm{KOH}$ solution. The number of the transferred electrons $(n)$ was calculated by the Koutecky-Levich equations described as follows.

$$
\frac{1}{\mathrm{~J}}=\frac{1}{J_{K}}+\frac{1}{B \omega^{1 / 2}}
$$




$$
n=\frac{B}{0.2 F\left(D_{0}\right)^{2 / 3}(V)^{-1 / 6} C_{O_{2}}}
$$

where the $J, J_{k}, \omega, n, F, D_{0}, v$, and $C_{O_{2}}$ is the experimentally obtained current, the mass-transport free kinetic current, the rotation rate (rpm), the number of the transferred electrons, the Faraday's constant $(96485 \mathrm{C} / \mathrm{mol})$, the diffusion coefficient of oxygen $\left(1.9 \times 10^{-5} \mathrm{~cm} / \mathrm{s}, 0.1 \mathrm{~mol} / \mathrm{L} \mathrm{KOH}\right)$, the kinematic viscosity of the electrolyte $\left(0.01 \mathrm{~cm}^{2} / \mathrm{s}\right)$, and the concentration of molecular oxygen in the $0.1 \mathrm{~mol} / \mathrm{L} \mathrm{KOH}$ solution $\left(1.2 \times 10^{-3} \mathrm{~mol} / \mathrm{L}\right)$, respectively.

\section{Results And Discussion}

The iron-chelating pyridine nitrogen-rich coordinated nanosheet (IPNCN) composites were fabricated through a convenient process, as schemed in Figure 1a-1b. First, the 1,10-phenanthroline-5,6-quinone were used as the raw materials to obtain the yellow powder products of the TP through the condensation of schiff-base reaction. Then, the nitrogen elements at both ends of the TP were coordinated with the iron ions from ferrous chloride to form the coordination polymers in the ethanol/water solution under the solvothermal conditions at $90^{\circ} \mathrm{C}$. The thus-formed coordination polymers were purified through washing and centrifugation, and then the targeted products of reddish-brown powders (the IPNCN precursors) were obtained. Finally, in order to achieve the better ORR catalytic performance, the IPNCN precursors were calcined at different temperatures $\left(750-900^{\circ} \mathrm{C}\right)$ in the nitrogen atmosphere. After cooling to room temperature, the calcined products were stirred in the $1 \mathrm{~mol} / \mathrm{L}$ hydrochloric acid to remove the inactive and metal oxides produced in the heating process [13].

The structures of the TP were determined by the MALDI-TOF mass spectrum (Figure 1c), ${ }^{1} \mathrm{H}$ NMR spectrum (Figure S1a), and ${ }^{13} \mathrm{C}$ NMR spectrum (Figure S1b). A significant peak at $384.8 \mathrm{~m} / \mathrm{z}$ was found in the MALDI-TOF mass spectrum (Figure 1c), which is consistent with the molecule weight of the TP. The ${ }^{1} \mathrm{H}$ NMR spectrum (Figure S1a) in the $\mathrm{CDCl}_{3}\left(1 \times 10^{-3} \mathrm{~mol} / \mathrm{L}\right)$ at $25^{\circ} \mathrm{C}$ displayed three highly resolved signals in the aromatic region, corresponding to the skeleton protons. In the solid-state ${ }^{13} \mathrm{C} \mathrm{NMR}$ spectrum (Figure S1b), the overlapping signals from 120 to 150 ppm belong to the aromatic carbons in the skeleton [14]. These results demonstrated that the novel organic ligands were successfully synthesized. The TP monomers contain up to $21.9 \%$ nitrogen element and both ends are pyridine nitrogen which can be coordinated with $\mathrm{Fe}^{2+}$, so that the TP and $\mathrm{Fe}^{2+}$ are alternately connected to form the coordination polymers with periodic repetitive structure units. The IPNCN precursors could be easily formed because of the strong coordination interactions between the nitrogen elements and the metal ions under high temperature and high pressure [15]. The TP and IPNCN composites were further characterized by Fourier transform infrared spectra (FT-IR) (Figure 1d). A new absorption band at $1022 \mathrm{~cm}^{-1}$ for the IPNCN $\left(\mathrm{TP} / \mathrm{Fe}^{2+}=1 / 1\right)$ composites was observed to be assigned to the characteristic of Fe-N bonds, indicating that the coordination polymers are successfully formed [16]. Also, the literature [17] and the Gaussian calculations have showed that the main skeleton of the TP is planar. Also, the coordination 
form of Fe-N bonds can be further proven by Gaussian calculations. The details of the Gaussian computational method, cartesian coordinates, and electronic energies for all the complexes calculated in the present study were presented in "S2. Gaussian calculations" in the Supporting Information. In the process of coordination with $\mathrm{Fe}^{2+}$, which plays a key role in connecting points, the different angles can be formed and covered between the planes, resulting in a change in thickness and length of nanosheet.

To obtain the coordination polymers with different degree of reaction, the different mass ratios of TP to $\mathrm{Fe}^{2+}$ were adjusted among $\mathrm{TP} / \mathrm{Fe}^{2+}=2 / 1, \mathrm{TP} / \mathrm{Fe}^{2+}=1 / 1$, and TP/Fe ${ }^{2+}=1 / 2$, named as IPNCN-1, IPNCN2 , and IPNCN-3, respectively. The IPNCN samples burning at different calcinate temperatures were denoted as IPNCN-1-850, IPNCN-2-X (X = 750, 800, 850, and 900), and IPNCN-3-850, where the last character of $X$ stands for the calcinate temperature. The TP-850 represents the TP samples which do not coordinate with metals and are calcined at $850^{\circ} \mathrm{C}$. Notably, the TP can also form the planar sheets due to the strong intermolecular large conjugated aromatic structures. The microstructures of the TP were characterized by the emission scanning electron microscopy (SEM) which shows the scale-like nanosheets (Figure 2a), indicating the consistency of the microstructures and the chemical structures. After coordinating with the metal ions through solvothermal method under high temperature and high pressure, the nanosheets still remain but the size was changed (Figure 2c) [18]. The reason is that the metal ions in the center can connect the planar flake structures and the both ends of the pyridine nitrogen from TP can coordinate with central metal ions at different angles in the three-dimensional space, resulting in the angle changes between the nanosheets [19]. The nanosheet morphologies of the TP were changed after calcination at $850^{\circ} \mathrm{C}$ in the nitrogen atmosphere, and the flake morphologies would shrink and accumulate (Figure 2b). However, the morphologies of the IPNCN-2-800, IPNCN-2-850, and IPNCN-3900 can be still maintained stable (Figure $2 \mathrm{~d}, 2 \mathrm{e}$, and $2 \mathrm{f}$ ), and the sheet is still sustained, reflecting that the coordination interactions are beneficial to improving the thermal stability of the large conjugated aromatic structures.

The stability at different calcination temperatures (Figure 2) was mainly benefited from the fully conjugated rigid planes of the TP and the rigid polymers of the IPNCN-2 composites. The planar structures of the TP are also capable of acting as the templates for metals, which is favorable to coordination with metals and full contact with oxygen during the oxygen reduction reaction process [20]. The advantage of such design is the homogeneous distribution of the nitrogen and the uniformly dispersed metal catalytic active sites [21], which prevents the agglomeration of the metals in the calcination process. Therefore, it can be convinced from the above-mentioned results and discussion that the self-stable carbonization strategy has been discovered, which would provide a reference for the selection of the stable catalytic materials.

To examine the chemical constitutions of the as-prepared IPNCN composites, the X-ray photoelectron spectroscopy (XPS) measurements were further performed, as presented in Figure 3 and Figure S2-S3 in the Supporting Information. The existence of the C, N, O, and Fe elements in the IPNCN-2-850 can be convinced from Figure 3a, corresponding to the spectra peaks around 285, 399, 531, and $715 \mathrm{eV}$, respectively. The chemical elements of the IPNCN-2-X composites were counted and summarized in Table 
1 , indicating that the nitrogen atoms have been successfully doped into the IPNCN-2-X composites. The high-resolution $\mathrm{C} 1 \mathrm{~s}$ spectra displayed four peaks at 284.58, 285.15, 286.12, and $288.56 \mathrm{eV}$ (Figure 3b), assigning to the $\mathrm{C}-\mathrm{C}, \mathrm{C}-\mathrm{N}, \mathrm{C}-\mathrm{O}$, and $\mathrm{C}=0$ groups, respectively [22]. The $\mathrm{N} 1 \mathrm{~s}$ peaks can be divided into 398.23, 400.24, 401.00, and $402.73 \mathrm{eV}$ (Figure 3c), corresponding to the pyridinic-N, pyrrolic-N, graphitic-N, and $\mathrm{N}$-oxide ( $\mathrm{N}-\mathrm{O})$, respectively [23]. The contents of the different nitrogen species were also calculated and listed in Table 1. It can be seen that pyridinic-N and graphitic- $\mathrm{N}$ still have relatively high contents at high temperature, and the pyridinic- $\mathrm{N}$ and graphitic- $\mathrm{N}$ can serve as the efficient active sites during the oxygen reduction reaction process [24]. The total nitrogen content decreases from 11.14 at. \% to 3.24 at. $\%$ with the increase of pyrolysis temperature from 750 to $900^{\circ} \mathrm{C}$ due to the decomposition of the N-C bonds at high temperature $[25,26]$. However, the proportion of the pyridinic-N $(27.8 \%$ in Table 1$)$ in the IPNCN-2-850 composites could still strongly support the outstanding oxygen reduction reaction activity. The high-resolution Fe 2p XPS spectra of the IPNCN-2-850 composites in Figure $3 \mathrm{~d}$ are divided into individual peaks [27]. The binding energy peak at 710.97, 714.08, 718.16, 723.30, and $725.76 \mathrm{eV}$ corresponds to the $2 p_{3 / 2}$ orbit of $\mathrm{Fe}^{2+}$, the $2 \mathrm{p}_{3 / 2}$ orbit of $\mathrm{Fe}^{3+}$, the satellite peak, the $2 \mathrm{p}_{1 / 2}$ orbit of $\mathrm{Fe}^{2+}$, and the $2 p_{1 / 2}$ orbit of $\mathrm{Fe}^{3+}$, respectively. The $\mathrm{Fe}^{2+}$ groups act as the role of the active sites, promoting the adsorption of $\mathrm{O}_{2}$ and boosting the catalytic activity of the IPNCN composites $[25,28,29]$.

Table 1

Summary of the nitrogen content and bonding state of the IPNCN-2 composite catalysts.

\begin{tabular}{|llllllll|}
\hline Sample & $\mathbf{C}$ & $\mathbf{N}$ & $\mathbf{0}$ & $\mathbf{F e}$ & \multicolumn{2}{l}{ XPS (N content \%) } & \\
\cline { 8 - 9 } & (at. \%) & (at. \%) & (at. \%) & (at. \%) & Pyridinic-N & Pyrrolic-N & Graphitic-N \\
\hline IPNCN-2-750 & 77.5 & 11.1 & 10.0 & 1.4 & 34.3 & 29.4 & 26.9 \\
\hline IPNCN-2-800 & 79.0 & 9.21 & 10.8 & 1.0 & 33.7 & 27.9 & 25.2 \\
\hline IPNCN-2-850 & 79.5 & 8.3 & 10.9 & 1.2 & 29.3 & 27.8 & 27.7 \\
\hline IPNCN-2-900 & 84.5 & 3.2 & 11.4 & 0.9 & 30.1 & 30.5 & 28.1 \\
\hline
\end{tabular}

The surface areas and pore structures of the IPNCN-2 composite catalysts were determined by the nitrogen isothermal adsorption-desorption measurements through the Brunauer-Emmett-Teller (BET) (Figure 4). The IPNCN-2-X composite catalysts exhibit an obvious of type- $\mathrm{H}_{4}$ isotherm characteristics (Figure 4a) with an increase of nitrogen absorption at both low and high pressure [29, 30], which is the characteristic of the disordered micro-/meso-porous materials. The details of the BET surface areas and pore size distributions of the IPNCN-2 composite catalysts were listed in Table 2. The BET surface area of the IPNCN-2-750, IPNCN-2-800, IPNCN-2-850, and IPNCN-2-900 composite catalysts is 13.0, 14.1, 12.0, and $34.2 \mathrm{~m}^{2} \mathrm{~g}^{-1}$, respectively. The changing surface of the measured samples is attributed to the small organic molecules produced by the decomposition at relatively high temperature. The IPNCN-2-X composite catalysts have the mesopores with large sizes and the nanopores with small sizes that can be beneficial for the catalysis process and provide the more abundant active sites, respectively [31]. 
Table 2

The BET surface areas and pore size distributions of the IPNCN-2 composite catalysts.

\begin{tabular}{|lllll|}
\hline Sample & $\mathrm{S}_{\mathrm{BET}}$ & \multicolumn{3}{c|}{ Pore volume $\left(\mathrm{mL} \mathrm{g}^{-1}\right)$} \\
\cline { 3 - 5 } & $\left.\mathbf{( m}^{\mathbf{2}} \mathbf{g}^{-1}\right)$ & Total & Micro & Meso \\
\hline IPNCN-2-750 & 13.000 & 0.030 & 0.011 & 0.021 \\
\hline IPNCN-2-800 & 14.100 & 0.040 & 0.013 & 0.029 \\
\hline IPNCN-2-850 & 12.000 & 0.040 & 0.005 & 0.037 \\
\hline IPNCN-2-900 & 34.223 & 0.091 & 0.026 & 0.064 \\
\hline
\end{tabular}

To explore the ORR catalytic performances, the cyclic voltammetry (CV) measurements in the $\mathrm{N}_{2}$ saturated and $\mathrm{O}_{2}$-saturated $0.1 \mathrm{~mol} / \mathrm{L}$ potassium hydroxide $(\mathrm{KOH})$ solution for the IPNCN-2-850 composite catalysts were further performed on a rotating disk electrode (RDE) at the scan rate of $50 \mathrm{mV}$ $\mathrm{s}^{-1}$ (Figure 5). Figure 5a depicts that the redox peak could not be found in the $\mathrm{N}_{2}$-saturated electrolyte, while a well-defined cathodic reduction peak at $0.80 \mathrm{~V}$ was clearly observed in the $\mathrm{O}_{2}$-saturated $\mathrm{KOH}$ electrolyte, suggesting an obvious intrinsic electrocatalytic activity for the ORR [32, 33]. For comparison, the apparent peak at $0.76,0.78$, and $0.80 \mathrm{~V}$ was observed for the IPNCN-2-750, IPNCN-2-800, and IPNCN2-900 composite catalysts in the $\mathrm{O}_{2}$-saturated electrolyte, respectively (Figure S4a). The cathodic reduction current peak at about $0.81 \mathrm{~V}$ ( $v s$. RHE) of the IPNCN-2-850 composite catalysts was higher than that of other samples (Figure 6a, Figure S4a, and Figure S4b), indicating that the IPNCN-2-850 composite catalysts have the best ORR activity among others. To further explore the electrocatalytic properties of the IPNCN-2-X composite catalysts, the linear sweep voltammogram (LSV) measurements were carried out by using the rotating disk electrode (RDE) in the $\mathrm{O}_{2}$-saturated $0.1 \mathrm{~mol} / \mathrm{L} \mathrm{KOH}$ solution (Figure $5 \mathrm{~b}$ ). The IPNCN-2-850 composite catalysts showed excellent onset potentials of $0.93 \mathrm{~V}$ and half-wave potentials of $0.84 \mathrm{~V}$ ( $v s$. RHE), which can compare to the commercial Pt/C catalysts with onset potentials of $0.96 \mathrm{~V}$ and half-wave potentials of $0.85 \mathrm{~V}$ ( $v s$. RHE). In addition, The ORR activity of the IPNCN-2-850 composite catalysts is more positive than the other IPNCN-2 composite catalysts at different temperatures (Figure $5 b$ ) and different mole ratios (Figure S4c), implying an excellent ORR performance for the stable IPNCN composite catalysts [34]. Furthermore, the limiting current density of the IPNCN-2-850 composite catalysts is also better than that of the $\mathrm{Pt} / \mathrm{C}$ catalysts. Therefore, the most proper temperature for preparing the IPNCN-2 composite catalysts is $850^{\circ} \mathrm{C}$, which could create the useful mesoporous structures and the higher pyridinic-N content to offer the more active sites and facilitate the efficient mass transfer. In addition, the planar structures could further provide sufficient contact points for oxygen to promote the ORR catalytic performance [35].

The linear sweep voltammetry (LSV) curves of the IPNCN-2-850 composite catalysts varying from 400 to $2400 \mathrm{rpm}$ in the $\mathrm{O}_{2}$-saturated $0.1 \mathrm{~mol} / \mathrm{L} \mathrm{KOH}$ solution were further presented in Figure $\mathrm{S} 4 \mathrm{~d}$. The limiting current density obtained from the LSV curves shows a rapid increase as the rotation speed increases, 
which is due to the decrease of the diffusion distance under high speed condition. The corresponding Koutecky-Levich (K-L) plots of the IPNCN-2-850 composite catalysts at different potentials exhibit a great linearity and some are overlapped (Figure $5 \mathrm{c}$ ), indicating a similar electron-transfer process. The electron transfer number $(n)$ of the IPNCN-2-850 composite catalysts was calculated as 3.9 in average at various potentials from 0.2 to $0.6 \mathrm{~V}$ according the $\mathrm{K}-\mathrm{L}$ plot (Figure $5 \mathrm{~d}$ ), indicating that the oxygen is reduced through a direct four-electron pathway.

For comparison, the TP catalysts were prepared via the same method for preparing the IPNCN-2-850 composite catalysts but without the addition of ferrous chloride, which were named as TP-850. The ORR activities of the TP-850 catalysts were observed as not good as the IPNCN-2-850 composite catalysts (Figure S4e and Figure S4f), suggesting the importance of the iron ions which are able to form the active sites. In order to prove the importance of the coordination interactions in the solvothermal process, the direct method of grinding TP and ferrous chloride was employed instead of the solvothermal method to prepare the Grind-TP-Fe-2-850 catalysts. The Grind-TP-Fe-2-850 catalysts also show the much lower onset potential and half-wave potential than the IPNCN-2-850 composite catalysts (Figure S4e and Figure S4f), indicating that the solvothermal method is conducive to form the coordination polymers and the uniform dispersion of the active sites [36-38].

In addition to the ORR activity, the electrochemical stability is another important aspect for the ORR catalysts in practical applications. The methanol resistance and electrochemical durability of the IPNCN2-850 composite and Pt/C catalysts were characterized by the chronoamperometry measurements. After injecting the solution of methanol $(1 \mathrm{~mol} / \mathrm{L})$, the $\mathrm{Pt} / \mathrm{C}$ catalysts show an immediate drop in the current density. However, there is no obvious change in the current density for the IPNCN-2-850 composite catalysts during the ORR process (Figure 5e), revealing that the IPNCN-2-850 composite catalysts have the great tolerance to the methanol. Moreover, another significant parameter to detect the catalytic performance is the electrochemical durability, as illustrated in Figure 5f. The IPNCN-2-850 composite catalysts still keep $97.7 \%$ of the initial current while the Pt/C catalysts retain only $69 \%$ of the initial current after 40000 seconds (Figure 5f). It could be concluded that the as-prepared IPNCN-2-850 composite catalysts possess the much better methanol tolerance and electrochemical durability [39].

\section{Conclusions}

In summary, the novel planar organic ligands (IPNCN composites) were successfully designed and synthesized, where the large content of pyridine nitrogen and full conjugated systems are beneficial to improving the structural stability. The IPNCN composites can be served as the templates for metal ions through the solvothermal method to obtain the more stable catalyst precursors. The design strategy of IPNCN composite catalysts is conducive to self-stabilization in high temperature environment. The results revealed that the as-prepared IPNCN composite catalysts possess the more excellent ORR catalytic performance in the alkaline solutions compared to the commercial $\mathrm{Pt} / \mathrm{C}$ catalysts. The superior catalytic activity of the IPNCN composite catalysts can be attributed to the rich content of pyridine nitrogen, the stable and uniform distribution of the nitrogen elements and the metal catalyzed active sites. The 
methanol resistance and electrochemical durability of the IPNCN composite catalysts are much better than those of the commercial Pt/C catalysts in the alkaline media. It could be convinced that the asdesigned IPNCN composite catalysts would be a promising alternative to the noble metal Pt-based catalysts in the practical applications.

\section{Abbreviations}

OOR

Oxygen reduction reaction

IPNCN

Iron-chelating pyridine nitrogen-rich coordinated nanosheet

TP

Tetrapyrido $\left[3,2-a: 2^{\prime}, 3^{\prime}-c: 3^{\prime \prime}, 2^{\prime \prime}-h: 2^{\prime \prime \prime}, 3^{\prime \prime}-j\right]$ phenazine

M-N/C

Metal-nitrogen/carbon

RHE

Reference hydrogen electrode

XPS

X-ray photoelectron spectroscopy

DI water

Deionized water

\section{FESEM}

Field-emission scanning electron microscopy

BET

Brunauer-Emmett-Teller

CV

Cyclic voltammetry (CV)

\section{LSV}

Linear sweep voltammetry

\section{RDE}

Rotating disk electrode

K-L

Koutecky-Levich

i-t

Current-time

$\mathrm{n}$

Number of the transferred electrons

$\mathrm{J}$

Experimentally obtained current

$J_{k}$ 
Mass-transport free kinetic current

$\omega$

Rotation rate (rpm)

$\mathrm{F}$

Faraday's constant $(96485 \mathrm{C} / \mathrm{mol})$

$\mathrm{D}_{0}$

Diffusion coefficient of oxygen $\left(1.9 \times 10^{-5} \mathrm{~cm} / \mathrm{s}, 0.1 \mathrm{~mol} / \mathrm{L} \mathrm{KOH}\right)$

$\mathrm{V}$

Kinematic viscosity of the electrolyte $\left(0.01 \mathrm{~cm}^{2} / \mathrm{s}\right)$

\section{Declarations}

\section{Availability of data and materials}

All data generated or analyzed during this study are included in this published article and its supplementary information files.

\section{Competing interests}

The authors declare that they have no competing interests.

Funding

This work was financially supported by the National Natural Science Foundation of China (52122303, $21875033,52103074)$, the Natural Science Foundation of Shanghai (21ZR1402800), and the China Postdoctoral Science Foundation (2021M690597).

\section{Authors' contributions}

BZ carried out the whole study and drafted the manuscript. HG participated the preparations and characterizations. LZ participated the characterizations, helped to draft the manuscript. XZ analyzed the results of characterizations, reviewed the manuscript, and provided the funding supports. CZ conceived of the study, concluded the results, reviewed the manuscript, and provided the funding supports. TL leaded the whole study, helped to conceive of the study, and provided the funding supports. All the authors have read and approved the final manuscript.

\section{Acknowledgements}

Supports from the National Natural Science Foundation of China $(52122303,21875033,52103074)$, the Natural Science Foundation of Shanghai (21ZR1402800), and the China Postdoctoral Science Foundation (2021M690597) are appreciated. 
Not applicable.

\section{Consent for publication}

Not applicable.

\section{References}

1. J. Han, J. Bian, C. Sun. Recent advances in single-atom electrocatalysts for oxygen reduction reaction. Research 2020 (2020) 9512763.

2. G. J. He, Y. Y. Liu, D. E. Gray, J. Othon. Conductive polymer composites cathodes for rechargeable aqueous Zn-ion batteries: A mini-review. Composites Communications 27 (2021) 100882.

3. C. Cui, L. Gan, M. Heggen, S. Rudi, P. Strasser. Compositional segregation in shaped Pt alloy nanoparticles and their structural behaviour during electrocatalysis. Nature Materials 12 (2013) 765771.

4. D. Zhao, Z. Zhuang, X. Cao, C. Zhang, Q. Peng, C. Chen, Y. Li. Atomic site electrocatalysts for water splitting, oxygen reduction and selective oxidation. Chemical Society Reviews 49 (2020) 2215-2264.

5. Y. Chen, S. Ji, Y. Wang, J. Dong, W. Chen, Z. Li, R. Shen, L. Zheng, Z. Zhuang, D. Wang, Y. Li. Isolated single iron atoms anchored on $\mathrm{N}$-doped porous carbon as an efficient electrocatalyst for the oxygen reduction reaction. Angewandte Chemie International Edition 56 (2017) 6937-6941.

6. Z. P. Wang, L. Chen, S. D. Xu, D. Zhang, X. X. Zhou, X. Wu, X. M. Xie, X. Y. Qiu. Cobalt vanadium layered double hydroxide/FeOOH heterostructure catalyst with strong electron interactions for stable oxygen evolution performance. Composites Communications 27 (2021) 100780.

7. L. Wu, L. Yu, X. Xiao, F. Zhang, S. Song, S. Chen, Z. Ren. Recent advances in self-supported layered double hydroxides for oxygen evolution reaction. Research 2020 (2020) 3976278.

8. G. Wu, K. L. More, C. M. Johnston, P. Zelenay. High-performance electrocatalysts for oxygen reduction derived from polyaniline, iron, and cobalt. Science 332 (2011) 443-447.

9. K. Gong, F. Du, Z. Xia, M. Durstock, L. Dai. Nitrogen-doped carbon nanotube arrays with high electrocatalytic activity for oxygen reduction. Science 323 (2009) 760-764.

10. Y. Nie, L. Li, Z. Wei. Recent advancements in Pt and Pt-free catalysts for oxygen reduction reaction. Chemical Society Reviews 44 (2015) 2168-2201.

11. D. Guo, R. Shibuya, C. Akiba, S. Saji, T. Kondo, J. Nakamura. Active sites of nitrogen-doped carbon materials for oxygen reduction reaction clarified using model catalysts. Science 351 (2016) 361-365.

12. X. Y. Cui, S. B. Yang, X. X. Yan, J. G. Leng, S. Shuang, P. M. Ajayan, Z. J. Zhang. Pyridinic-nitrogendominated graphene aerogels with Fe-N-C coordination for highly efficient oxygen reduction reaction. Advanced Functional Materials 26 (2016) 5708-5717.

13. Q. Lai, L. Zheng, Y. Liang, J. He, J. Zhao, J. Chen. Metal-organic-framework-derived Fe-N/C electrocatalyst with five-coordinated $\mathrm{Fe}^{-} \mathrm{N}_{X}$ sites for advanced oxygen reduction in acid media. ACS Catalysis 7 (2017) 1655-1663. 
14. B. Zhang, X. Zhang, K. Wan, J. Zhu, J. Xu, C. Zhang, T. Liu. Dense hydrogen-bonding network boosts ionic conductive hydrogels with extremely high toughness, rapid self-recovery, and autonomous adhesion for human-motion detection. Research 2021 (2021) 9761625.

15. C. Tang, Q. Zhang. Nanocarbon for oxygen reduction electrocatalysis: Dopants, edges, and defects. Advanced Materials 29 (2017) 160413.

16. M. Jahan, Q. Bao, K. P. Loh. Electrocatalytically active graphene-porphyrin MOF composite for oxygen reduction reaction. Journal of the American Chemical Society 134 (2012) 6707-6713.

17. Y. F. Song, P. Yang. Mononuclear tetrapyrido [3,2-a: 2,3 ' $-c: 3^{\prime \prime}, 2$ " $\left.-h: 22^{\prime \prime \prime}, 3^{\prime \prime}-1\right]$ phenazine (tpphz) cobalt complex. Polyhedron 20 (2001) 501-506.

18. Y. Mun, M. J. Kim, S. A. Park, E. Lee, Y. Ye, S. Lee, Y. T. Kim, S. Kim, O. H. Kim, Y. H. Cho, Y. E. Sung, J. Lee. Soft-template synthesis of mesoporous non-precious metal catalyst with $\mathrm{Fe}-\mathrm{N}_{X} / \mathrm{C}$ active sites for oxygen reduction reaction in fuel cells. Applied Catalysis B-Environmental 222 (2018) 191-199.

19. S. Liu, Z. Wang, S. Zhou, F. Yu, M. Yu, C. Y. Chiang, W. Zhou, J. Zhao, J. Qiu. Metal-organicframework-derived hybrid carbon nanocages as a bifunctional electrocatalyst for oxygen reduction and evolution. Advanced Materials 29 (2017) 1700874.

20. J. Wang, S. Kattel, Z. Wang, J. G. Chen, C. J. Liu. L-phenylalanine-templated platinum catalyst with enhanced performance for oxygen reduction reaction. ACS Applied Materials \& Interfaces 10 (2018) 21321-21327.

21. H. W. Liang, W. Wei, Z. S. Wu, X. Feng, K. Mullen. Mesoporous metal-nitrogen-doped carbon electrocatalysts for highly efficient oxygen reduction reaction. Journal of the American Chemical Society 135 (2013) 16002-16005.

22. W. J. Jiang, L. Gu, L. Li, Y. Zhang, X. Zhang, L. J. Zhang, J. Q. Wang, J. S. Hu, Z. Wei, L. J. Wan. Understanding the high activity of Fe-N-C electrocatalysts in oxygen reduction: $\mathrm{Fe} / \mathrm{Fe}_{3} \mathrm{C}$ nanoparticles boost the activity of $\mathrm{Fe}_{\mathrm{N}}$. Journal of the American Chemical Society 138 (2016) 3570-3578.

23. J. Guo, Y. Li, Y. Cheng, L. Dai, Z. Xiang. Highly efficient oxygen reduction reaction electrocatalysts synthesized under nanospace confinement of metal-organic framework. ACS Nano 11 (2017) 83798386.

24. Y. Zhu, B. Zhang, X. Liu, D. W. Wang, D. S. Su. Unravelling the structure of electrocatalytically active Fe-N complexes in carbon for the oxygen reduction reaction. Angewandte Chemie International Edition 53 (2014) 10673-10677.

25. J. Hu, L. J. Cao, Z. Y. Wang, J. L. Liu, J. N. Zhang, Y. L. Cao, Z. G. Lu, H. Cheng. Hollow high-entropy metal organic framework derived nanocomposite as efficient electrocatalyst for oxygen reduction reaction. Composites Communications 27 (2021) 100866.

26. K. Chen, K. Liu, P. An, H. Li, Y. Lin, J. Hu, C. Jia, J. Fu, H. Li, H. Liu, Z. Lin, W. Li, J. Li, Y. R. Lu, T. S. Chan, N. Zhang, M. Liu. Iron phthalocyanine with coordination induced electronic localization to boost oxygen reduction reaction. Nature Communications 11 (2020) 4173. 
27. F. L. Meng, Z. L. Wang, H. X. Zhong, J. Wang, J. M. Yan, X. B. Zhang. Reactive multifunctional template-induced preparation of Fe-N-doped mesoporous carbon microspheres towards highly efficient electrocatalysts for oxygen reduction. Advanced Materials 28 (2016) 7948-7955.

28. G. Yang, J. Zhu, P. Yuan, Y. Hu, G. Qu, B. A. Lu, X. Xue, H. Yin, W. Cheng, J. Cheng, W. Xu, J. Li, J. Hu, S. $\mathrm{Mu}, \mathrm{J}$. N. Zhang. Regulating Fe-spin state by atomically dispersed Mn-N in Fe-N-C catalysts with high oxygen reduction activity. Nature Communications 12 (2021) 1734.

29. Y. Zheng, S. Chen, K. A. I. Zhang, J. Zhu, J. Xu, C. Zhang, T. Liu. Ultrasound-triggered assembly of covalent triazine framework for synthesizing heteroatom-doped carbon nanoflowers boosting metalfree bifunctional electrocatalysis. ACS Applied Materials \& Interfaces 13 (2021) 13328-13337.

30. X. Tang, Y. Wu, W. Zhai, T. Chu, L. Li, B. Huang, T. Hu, K. Yuan, Y. Chen. Iron-based nanocomposites implanting in N, P Co-doped carbon nanosheets as efficient oxygen reduction electrocatalysts for ZnAir batteries. Composites Communications (2021) 100994. (doi: https://doi.org/10.1016/j.coco.2021.100994)

31. A. Serov, K. Artyushkova, P. Atanassov. Fe-N-C oxygen reduction fuel cell catalyst derived from carbendazim: Synthesis, structure, and reactivity. Advanced Energy Materials 4 (2014) 1301735.

32. J. Shui, M. Wang, F. Du, L. Dai. N-doped carbon nanomaterials are durable catalysts for oxygen reduction reaction in acidic fuel cells. Science Advances 1 (2015) e1400129.

33. X. Zhang, W. Fan, T.X. Liu. Fused deposition modeling 3D printing of polyamide-based composites and its applications. Composites Communications 21 (2020) 100413.

34. H. J. Shen, E. Gracia-Espino, J. Y. Ma, H. D. Tang, X. Mamat, T. Wagberg, G. Z. Hu, S. J. Guo. Atomically $\mathrm{FeN}_{2}$ moieties dispersed on mesoporous carbon: A new atomic catalyst for efficient oxygen reduction catalysis. Nano Energy 35 (2017) 9-16.

35. W. P. van den Wildenberg, G. J. van Boxtel, M. W. van der Molen, D. A. Bosch, J. D. Speelman, C. H. Brunia. Stimulation of the subthalamic region facilitates the selection and inhibition of motor responses in Parkinson's disease. Journal of Cognitive Neuroscience 18 (2006) 626-636.

36. C. Zhang, Y. C. Wang, B. An, R. Huang, C. Wang, Z. Zhou, W. Lin. Networking pyrolyzed zeolitic imidazolate frameworks by carbon nanotubes improves conductivity and enhances oxygenreduction performance in polymer-electrolyte-membrane fuel cells. Advanced Materials 29 (2017) 1604556.

37. J. D. Yi, R. Xu, Q. Wu, T. Zhang, K. T. Zang, J. Luo, Y. L. Liang, Y. B. Huang, R. Cao. Atomically dispersed iron-nitrogen active sites within porphyrinic triazine-based frameworks for oxygen reduction reaction in both alkaline and acidic media. ACS Energy Letters 3 (2018) 883-889.

38. Y. Z. Su, Z. Q. Yao, F. Zhang, H. Wang, Z. Mics, E. Canovas, M. Bonn, X. D. Zhuang, X. L. Feng. Sulfurenriched conjugated polymer nanosheet derived sulfur and nitrogen co-doped porous carbon nanosheets as electrocatalysts for oxygen reduction reaction and zinc-air battery. Advanced Functional Materials 26 (2016) 5893-5902.

39. S. Jin, C. Li, L. K. Shrestha, Y. Yamauchi, K. Ariga, J. P. Hill. Simple fabrication of titanium dioxide/Ndoped carbon hybrid material as non-precious metal electrocatalyst for the oxygen reduction 
reaction. ACS Applied Materials \& Interfaces 9 (2017) 18782-18789.

\section{Figures}

\section{Figure 1}

(a) Schematic of the preparation of the iron-chelating pyridinic nitrogen-rich coordinated nanosheet (IPNCN) composites. (b) Optimized geometry of the tetrapyrido [3,2-a:2',3'-c:3",2"-h:2"',3"'-j] phenazine (TP) and the IPNCN composites by Gaussian calculations. (c) MALDI-TOF mass spectrum of the TP. (d) FT-IR spectra of the TP and the IPNCN (TP/Fe2+ = 1/1) composites.

\section{Figure 2}

SEM image of the (a) TP, (b) TP-850, (c) IPNCN-2 composites, (d) IPNCN-2-800 composites, (e) IPNCN-2850 composites, and (f) IPNCN-2-900 composites.

\section{Figure 3}

(a) XPS survey spectra of the IPNCN-2-850 composites. The high-resolution (b) C 1s, (c) N 1s, and (d) Fe $2 p$ XPS spectra of the IPNCN-2-850 composites.

\section{Figure 4}

(e) Nitrogen sorption/desorption isotherms and (f) half pore-size distributions of the IPNCN-2 composite catalysts prepared at different pyrolytic temperatures.

\section{Figure 5}

(a) CV curves of the IPNCN-2-850 composite catalysts in the N2-saturated and 02-saturated $0.1 \mathrm{~mol} / \mathrm{L}$ aqueous $\mathrm{KOH}$ solutions. (b) LSV curves of the IPNCN-2 composite catalysts prepared at different pyrolytic temperatures and the commercial $\mathrm{Pt} / \mathrm{C}$ catalysts at $1600 \mathrm{rpm}$ rotation rate in the 02 -saturated $0.1 \mathrm{~mol} / \mathrm{L} \mathrm{KOH}$ solution. (c) K-L plots for the IPNCN-2-850 composite catalysts at different electrode potentials from 0.60 to $0.80 \mathrm{~V}$ (vs RHE). (d) Calculated electron transfer number of the IPNCN-2-850 composite catalysts. (e) Methanol tolerance evaluation of the IPNCN-2-850 composite and Pt/C catalysts. (f) Current-time (i-t) test of the IPNCN-2-850 composite catalysts at $1600 \mathrm{rpm}$ rotation rate in the 02 -saturated $0.1 \mathrm{~mol} / \mathrm{L} \mathrm{KOH}$ solution. 


\section{Supplementary Files}

This is a list of supplementary files associated with this preprint. Click to download.

- SupportingInformation.docx 